\title{
Development of slide agglutination test for the rapid diagnosis of Mycoplasma infection in the chicken
}

\author{
M. Arefin, J. A. Begum, R. Parvin, M. M. Rahman, M. A. H. N. A. Khan and \\ E. H. Chowdhury* \\ Department of Pathology, Faculty of Veterinary Science, Bangladesh Agricultural \\ University, Mymensingh-2202, Bangladesh,
}

\begin{abstract}
Mycoplasma gallisepticum is considered to be the most important pathogenic Mycoplasma sp. and occurs world-wide. For effective control of mycoplasmosis, early diagnosis is the cornerstone, but the cultural method is laborious, expensive and timeconsuming, whereas agglutination test is easy to perform in field conditions and cheaper. Mycoplasma gallisepticum was isolated and two types of stained antigen produced. The antigen produced distinct tiny clumps with positive antisera of Mycoplasma spp. The slide agglutination system was sensitive, reliable and cheap. This method may be used to screen Mycoplasma infections in poultry farms. (Bangl. vet. 2011. Vol. 28, No. 2, 80 - 84)
\end{abstract}

\section{Introduction}

Mycoplasma is one of the major avian diseases in the emerging poultry industry in Bangladesh. Primarily, this is a disease of chickens and turkeys but it also infects many other domestic and wild birds (Jordan and Amin, 1980; Bradbury et al., 1993). The disease is caused by four common pathogens: Mycoplasma gallisepticum, M. synoviae, M. meleagridis and M. iowae (Bradbury, 2001). Mycoplasma synoviae (MS) causes infectious synovitis or mild upper respiratory disease. Mycoplasma gallisepticum (MG) causes respiratory disease and is the most economically important avian mycoplasma (Ley and Yoder, 1997). Diagnostic laboratories are trying to reduce the time required for diagnosis of Mycoplasma infections. Usually it takes approximately 7 days to culture and identify Mycoplasma. This method is tedious and confers little guarantee of sensitivity and species specificity. Several serological tests have been used to detect M. gallisepticum antibodies (Jordan and Amin, 1980). The most commonly used serological tests are the rapid serum agglutination (RSA) test, haemagglutination inhibition (HI) test, agar gel immuno-diffusion (AGID) test, and enzyme-linked immunosorbent assay (ELISA) (Avakian et al., 1988). Tube agglutination test for Mycoplasma disease was described by Thomas (1970), and microagglutination test by Harry and Yoder (1982). In Bangladesh, a commercially available Methylene-blue-stained Mycoplasma gallisepticum (MG) antigen is being used for RSA test to screen flocks. But this antigen, besides being less sensitive, is neither cheaper nor produced from a Bangladeshi isolate. It is difficult to read the result due to its strong colour background. The micro-agglutination (MA) system (microtest) has

\footnotetext{
*Corresponding author:- E-mail: emdad001@yahoo.com
} 
been adapted for a wide variety of serological procedures due to its better sensitivity (Anonymous, 1970; Witlin, 1967). So far, no attempt has been undertaken to produce a stained antigen from a local Mycoplasma isolate in Bangladesh. Production of tetrazolium-stained antigen from a local isolate might be more sensitive and cheaper. The present study was designed to prepare Mycoplasma-coloured antigen, develop slide micro-agglutination and agglutination tests for the diagnosis of avian mycoplasmosis.

\section{Materials and Methods}

Production of seeds

Mycoplasma was maintained in Mycoplasma agar in the laboratory and the isolates were plated on Mycoplasma agar, and a fried-egg-like single colony was selected for each isolate (Fig. 1). This was transferred to Mycoplasma broth and incubated at $37^{\circ} \mathrm{C}$ for 48 hours and maintained by transferring from one agar plate to another for several months. Kanamycin was added to the medium to prevent the growth of Gram-negative bacteria, and horse serum was used for the growth of Mycolasma organism. This culture was used for the production of stained antigens.

\section{Preparation of mycoplasma-stained colour antigen}

The local isolate of Mycoplasma gallisepticum was transferred to a conical flask containing $50 \mathrm{ml}$ of Mycoplasma broth base, which was incubated for 11 days at $37^{\circ} \mathrm{C}$, at which time each flask revealed dense growth. Fifty $\mathrm{ml}$ broth culture was divided into two conical flasks each containing $25 \mathrm{ml}$. Tetrazolium blue and neotetrazolium chloride were added aseptically, $0.5 \%$ to each culture. The flasks were agitated and incubated for 24 hours, then $0.5 \%$ phenol was added to each flask, which were incubated for a further 2 hours for inactivation. The stained broth suspension was filtered through sterile gauze and poured into eppendorf tubes. These were centrifuged at 14,000 rpm for 15 minutes. The supernatant fluid was decanted and the packed cells were suspended in $0.5 \%$ phenol saline. The suspension was vortexed vigorously with a few sterile glass beads and transferred to another eppendorf tube. A dense suspension of deeply stained cells resulted. The solution was kept at $4^{\circ} \mathrm{C}$ as neotetrazolium- and tetrazolium-stained antigen for future use. The total protein concentration of stained antigen was measured by the Folin Phenol method as described by Lowry et al. (1951) and the protein concentration was adjusted to 6.4 $\mathrm{ng} / \mu \mathrm{l}$ with the help of BSA standard curve. The antigen was packaged for field use.

\section{Collection of field samples}

A total of 110 serum samples were collected from local markets and poultry farms into eppendorf tubes. The slide micro-agglutination test was performed with the new Mycoplasma antigen. For development of slide micro-agglutination test, $20 \mu \mathrm{l}$ of stained antigen and $20 \mu \mathrm{l}$ chicken sera were placed on a sterile glass slide by a micropipette and mixed thoroughly by stirring. The results were read within 1 
minute. Serum and water were used as negative control. For proper mixing, the antigen was shaken before use. The stain that used for preparation of antigen was sensitive to light so it kept away from the light.

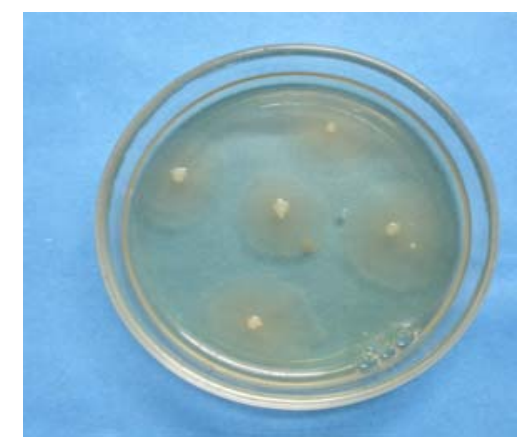

Fig. 1. White colour Mycoplasma colony showing a dense raised centre in colonies with typical fried egg appearance

\section{Results and Discussion}

Production of seeds

A single colony of Mycoplasma gallisepticum from Mycoplasma agar inoculated into Mycoplasma broth formed confluent growth that showed turbidity and sliminess (Fig. 2).

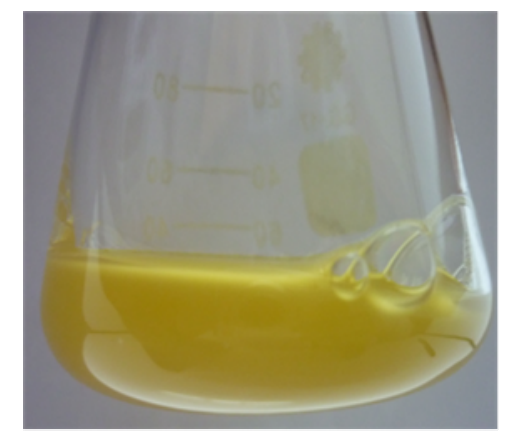

Fig. 2. Bulk culture of Mycoplasma gallisepticum in Mycoplasma broth showing turbidity and sliminess

\section{Stained antigen preparation}

The neotetrazolium-stained Mycoplasma antigen showed pink (Fig. 3), and the agglutination result was easily seen. The tetrazolium-stained Mycoplasma antigen showed light blue (Fig. 4) and the result was seen easily.

\section{Slide micro-agglutination test}

In positive case, granules (agglutinates) formed rapidly due to combination of homologous antigen and antibody, which was seen during rocking. In case of neotetrazolium-stained antigen the agglutinin was pink with purple background 
(Fig. 5). For tetrazolium-stained antigen the agglutinin was deep blue with light blue background (Fig. 6) and less easily seen. Granules developed within one minute with tetrazolium stain and two minutes with neotetrazolium stain. Since the agglutinins were suspended on colourless serum, they were easily visible to the naked eye. In conventional agglutination test with other commercial antigens the cloudy reaction was not easy to detect. The specificity of the stained antigen was good: it did not react with the negative control serum or with water.

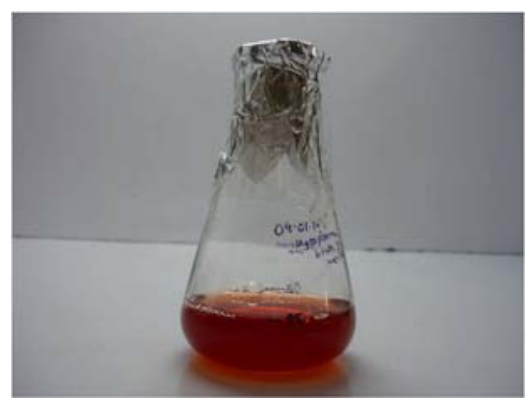

Fig. 3. Mycoplasma broth containing neotetrazolium stain

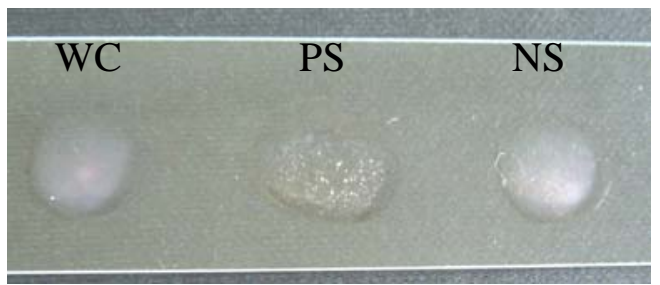

Fig. 5. Agglutination within two minutes with positive sera, negative sera and control with Neotetrazolium stained antigen

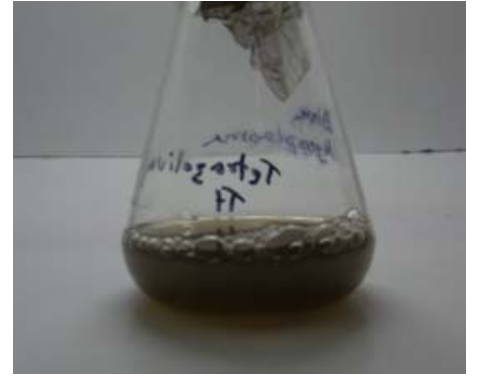

Fig. 4. Mycoplasma broth containing tetrazolium blue stain

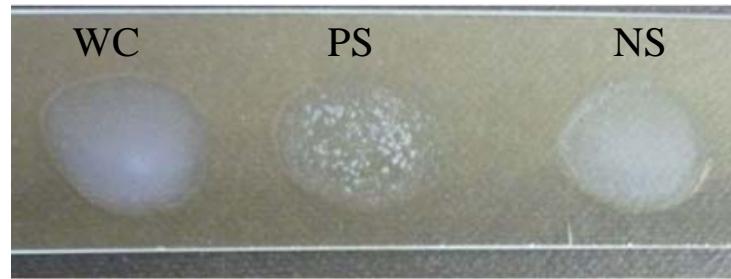

Fig. 6. Agglutination within one minute with positive sera (PS), negative sera (NS) and control (WC) with Tetrazolium stained antigen

Validation results with field samples

Among the 110 serum samples tested, 9\% were positive, $82 \%$ negative and $9 \%$ suspect. The indigenous birds showed the highest prevalence at $50 \%$. Broilers showed $15.9 \%$ positive. Growing birds showed no positive case (Table 1).

Table 1. Screening of field sera using new Mycoplasma stained antigen

\begin{tabular}{l|c|c|cc|cccc}
\hline \multirow{2}{*}{ Birds } & \multirow{2}{*}{$\begin{array}{c}\text { Number of } \\
\text { samples }\end{array}$} & \multirow{2}{*}{$\begin{array}{c}\text { Age in } \\
\text { weeks }\end{array}$} & \multicolumn{6}{c}{ Agglutination result } \\
\cline { 5 - 9 } & & & & Positive & Suspect & Negative \\
\hline Indigenous bird & 6 & $28-32$ & 3 & $50.0 \%$ & 0 & $0 \%$ & 3 & $50.0 \%$ \\
Broiler & 44 & $4.5-5.0$ & 7 & $15.9 \%$ & 0 & $0 \%$ & 37 & $84.1 \%$ \\
Growing bird (East shed) & 20 & $52.1-78.2$ & 0 & $0 \%$ & 2 & $10.0 \%$ & 18 & $90.0 \%$ \\
Growing bird (West shed) & 40 & $52.1-78.2$ & 0 & $0 \%$ & 8 & $20.0 \%$ & 32 & $80.0 \%$ \\
\hline
\end{tabular}




\section{Conclusions}

A tetrazolium-stained Mycoplasma antigen from a local isolate was successfully developed. [With the elapse of time, the stained antigen may react with the nonspecific antibody present in the serum. Therefore, results within one minute were indicated suspecting cases of mycoplasmosis. After testing specificity with other closely related organism and sensitivity with some commercial antigen, a test kit may be prepared.

\section{References}

Anonymous 1970: A selected bibliography of micro methods in microbiology with special emphasis on microtiter techniques. Cooke Engineering Co., Alexandria, Va, USA.

Avakian AP, Kleven SH, Glisson JR 1988: Evaluation of the specificity and sensitivity of two commercial ELISA kits, the SPAT, and the HI test for antibodies formed in response to Mycoplasma gallisepticum. Avian Diseases 32 262-272.

Bradbury JM, Abdul Wahab, Yavari CA, Dipiellet JP, Bove JM 1993: Mycoplasma imitates SP. Nov. is related to Mycoplasma gallisepticum and found in birds. Int. Journal of Systemic Bacteriology 43 721-728.

Bradbury JM 2001. Avian mycoplasmas. In: Poultry Diseases, $5^{\text {th }}$ edn, Jordan F, Pattison M, Alexander D. \& Faragher T, eds. WB Saunders, London, UK pp. 178-193.

Harry W, Yoder JR 1982: Microagglutination test for detection of antibodies to Mycoplasma gallisepticum and M. synoviae in avian sera. Avian Diseases 26 606-611.

Jordan FTW, Amin MM 1980: A survey of Mycoplasma infections in domestic poultry. Research in Veterinary Science 28 96-100.

Ley DH, Yoder HW 1997: Mycoplasma gallisepticum infection. In: Calnek BW (eds,). Diseases of poultry. 10 $0^{\text {th }}$ edn. Iowa State University Press, Ames, Iowa, USA pp. 194-207.

Lowry OH., Rosbrough NJ., Farr AL., and Randall RJ. 1951. Protein measurement with the Folin phenol reagent. Journal of Biological Chemistry 193 265-275.

Thomas H, Harry W, Yoder JR 1970: Preparation of Mycoplasma synoviae antigen for the tube agglutination test. Avian Diseases 15 462-466.

Witlin B 1967: Detection of antibodies by microtitration techniques. Mycopathol. Applied Microbiology 33 41-257. 